\title{
TINGKAT KERAWANAN KEBAKARAN HUTAN DAN LAHAN DI BANJARBARU PROVINSI KALIMANTAN SELATAN
}

\author{
Muhammad Riza Saputra $^{a}$, Deasy Arisanty ${ }^{a}$, Sidharta Adyatma $^{a}$ \\ a Program Studi Pendidikan Geografi, Fakultas Keguruan dan Ilmu Pendidikan, Universitas Lambung Mangkurat, \\ Banjarmasin, Provinsi Kalimantan Selatan, Indonesia
}

\section{ARTICLE INFO}

\section{Article history:}

Received: 15 April 2020

Accepted: 21 June 2021

Published: 30 June 2021

\section{Keywords:}

Fire Mapping; Land Cover; NDVI; Vegetation Density

\section{Corresponding author:}

Deasy Arisanty

Program Studi Pendidikan Geografi,

Universitas Lambung Mangkurat

Email: deasyarisanty@ulm.ac.id

\begin{abstract}
One of the areas in South Kalimantan that is prone to land fires is the Banjarbaru area, especially on peatlands. The fire in Banjarbaru is important because of the vital object of Syamsudin Noor Airport. Mapping of fire vulnerability was important for the Banjarbaru area, which had repeated fires throughout the year. The objective of the study was to analyze the vulnerability of forest and land fires in Banjarbaru, South Kalimantan Province. This study used Landsat 8 Oli Tirs imagery to obtain NDVI data and land cover maps from INA-Geoportal. The analysis of data used the scoring and overlay of the two maps. The level of vulnerability was dominated by the high vulnerability. The high level of vulnerability in Cempaka District was $81.9 \%$, in Banjarbaru Selatan District was around $99.5 \%$, in Banjarbaru Utara District was around $95.3 \%$, in Landasan Ulin District was around $94.1 \%$ and in Lianganggang District was around 88.9 $\%$. Land cover in the form of agriculture, plantations, and shrubs with moderatehigh density caused the land to be more prone to fires.
\end{abstract}

Copyright (C) 2021 The Authors This open access article is distributed under a Creative Commons Attribution (CC-BY) 4.0 International license

\section{Pendahuluan}

Kebakaran hutan dan lahan menjadi penyebab utama ancaman terhadap ekosistem hutan. Efek negatif dari kebakaran hutan dan lahan adalah pemanasan global, kesehatan manusia (Harrison et al., 2009; Sahani et al., 2014), kehilangan atau pengurangan keanekaragaman hayati, vegetasi, tanah (Certini, 2005), hidrologi dan kabut lintas batas. Insiden kebakaran hutan dan lahan yang tinggi di Asia Tenggara terjadi selama El Nino yang kuat yaitu pada tahun 1986-1987, 1994 dan 1997-1998 (Tacconi et al., 2008).

Kebakaran hutan dan lahan dapat dideteksi melalui citra satelit berdasarkan data hotspot (Razali et al., 2010; Sitanggang et al., 2013). MODIS dapat digunakan untuk mendeteksi hotspot dengan resolusi spasial (ukuran piksel) $1 \mathrm{~km}^{2}$ (Siegert \& Hoffmann, 2000). Pola hotspot digunakan untuk memprediksi kejadian kebakaran hutan dan lahan, sehingga memberikan informasi yang berguna untuk pengelolaan kebakaran hutan (Sitanggang et al., 2014).

Dampak dari kebakaran hutan dan lahan terhadap kehidupan manusia dan lingkungan sekitarnya adalah terjadinya penurunan kualitas lingkungan, dan berpengaruh terhadap kehidupan sosial, budaya dan ekonomi masyarakat (Jawad et al., 2015). Kebakaran ini juga berpengaruh terhadap kehidupan flora dan fauna, seperti terjadinya penurunan keanekaragaman hayati, dan terjadi kerusakan pada lingkungan flora dan fauna (Endrawati et al., 2018). Dampak lainnya adalah terhadap tanah, antara lain kemampuan untuk menyimpan air tanah, bahan organik pada tanah, $\mathrm{pH}$ tanah, dan kejenuhan basa (Murtinah et al., 2017; Rauf, 2016; Arisanty et al., 2020).

Faktor alam dan manusia menjadi penyebab terjadinya kebakaran. Faktor alam dapat terjadi karena adanya bencana alam misalnya adanya letusan gunungapi, dan adanya petir. Faktor manusia terjadi akibat adanya pembukaan lahan untuk perkebunan atau pertanian oleh masyarakat ataupun perusahaan 
Tabel 1. Skor tutupan lahan

\begin{tabular}{lll}
\hline No & Penutup Lahan & Skor \\
\hline 1 & Semak Belukar, Pertanian Lahan Kering Primer, Pemukiman/Transmigrasi, Sawah & 7 \\
2 & Belukar Rawa, Hutan Lahan Kering Sekunder, Hutan Tanaman Industri, Pertanian & 6 \\
& Lahan Kering + Semak & \\
3 & Hutan Rawa Sekunder, Perkebunan & 5 \\
4 & Hutan Lahan Kering Primer, Hutan Rawa Primer & 4 \\
5 & Hutan Mangrove Sekunder & 3 \\
6 & Hutan Mangrove Primer, Pertambangan & 2 \\
7 & Tambak, Tanah Terbuka, Bandara, Rawa, Tubuh Air & 1 \\
\hline
\end{tabular}

Sumber : Ruecker dalam Sabaraji (2005)

dengan cara membakar lahan. Aktivitas manusia membakar lahan paling berperan dalam peristiwa kebakaran hutan dan lahan (Arisanty et al., 2020, 2021). Kejadian kebakaran yang meningkat terdapat pada kawasan pertanian dan perkebunan (Saharjo \& Velicia, 2018).

Kebakaran hutan dan lahan di wilayah Kalimantan Selatan selalu terjadi setiap tahun. Kebakaran pada tahun 2015 berdasarkan data http://sipongi.menlhk.go.id seluas $196516.77 \mathrm{Ha}$; tahun 2016 seluas $2331.96 \mathrm{Ha}$; tahun 2017 seluas $8290.34 \mathrm{Ha}$; pada tahun 2018 seluas $98637.99 \mathrm{Ha}$; tahun 2019 seluas $137848.00 \mathrm{Ha}$ dan pada tahun 2020 seluas $3971.00 \mathrm{Ha}$. Jumlah titik panas di Provinsi Kalimantan Selatan tahun 2018 adalah 362 titik panas dengan jumlah tertinggi pada bulan September 2018. Jumlah titik panas di wilayah Kalimantan Selatan tahun 2019 sebanyak 907 titik, dengan titik panas tertinggi pada bulan September. Sedangkan pada tahun 2020, jumlah titik panas sebanyak 35 titik dengan jumlah titik panas terbanyak pada bulan September 2020. Salah satu wilayah Kalimantan Selatan yang rawan kebakaran lahan adalah wilayah Banjarbaru, terutama pada lahan gambut. Kebakaran di Banjarbaru menjadi penting karena adanya objek vital Bandara Syamsudin Noor (Arisanty et al., 2019, 2020).

Pemetaan tingkat kerawanan kebakaran hutan dan lahan di Banjarbaru penting dilakukan sebagai upaya untuk mengatasi kebakaran hutan dan lahan pada wilayah tersebut. Wilayah rawan kebakaran di Banjarbaru diidentifikasi melalui data tutupan lahan dan kerapatan vegetasi. Melalui pemetaan ini diharapkan penanganan kebakaran lebih tepat dilakukan sehingga wilayah yang rawan kebakaran dapat berkurang. Berdasarkan latar belakang, tujuan dari penelitian ini adalah untuk menganalisis kerawanan kebakaran hutan dan lahan di Banjarbaru, Provinsi Kalimantan Selatan.

\section{Metode}

Penelitian ini dilaksanakan di Banjarbaru yang merupakan wilayah rawan kebakaran hutan dan lahan. Tingkat kerawanan kebakaran lahan di Banjarbaru ditentukan berdasarkan data tutupan lahan dan nilai NDVI. Kebakaran lahan dilihat dari tutupan lahan dan nilai NDVI. Tutupan lahan diperoleh dari data INA-Geoportal sedangkan NDVI diperoleh dari Citra LANDSAT 8 OLI Tirs perekaman 20 Agustus 2018. Penelitian ini menggunakan skoring dan overlay antara peta tutupan lahan dan peta NDVI untuk menghasilkan peta tingkat kerawanan kebakaran hutan dan lahan di Banjarbaru.

\subsection{Penutupan Lahan}

Tutupan lahan menentukan kerawanan kebakaran hutan dan lahan karena tutupan lahan menentukan kecepatan penjalaran api. Tutupan lahan dengan campur tangan manusia seperti pada lahan pertanian akan mempercepat api menjalar karena adanya penyiapan lahan dan pengeringan lahan (Novita \& Vonnisa, 2021). Skor untuk tutupan lahan terdapat pada Tabel 1.

\subsection{Normalized Diffrerence Vegetation Index (NDVI)}

Metode yang digunakan dalam penelitian ini adalah metode Normalized Diffrerence Vegetation Index (NDVI). Metode NDVI ini menggunakan citra untuk mengidentifikasi tingkat kehijauan pada vegetasi sebagai pembagi nilai. Nilai NDVI dapat diperoleh melalui hasil perhitungan Near Infrared dan Red yang dipantulkan oleh tumbuhan, dengan rumus sebagai berikut: (NIR-RED)/(NIR+RED) $=($ BAND $5-$ BAND4)/(BAND 5 + BAND 4). Adapun klasifikasi dan skor untuk nilai NDVI terdapat pada Tabel 2.

\subsection{Tingkat Kerawanan Kebakaran lahan}

Kerawanan kebakaran lahan diperoleh dari skoring nilai tutupan lahan dan nilai kerapatan vegetasi yang diperoleh dari NDVI. Adapun kelas kerawanan kebakaran lahan terdapat pada Tabel 3. 
Tabel 2. Nilai rentang klasifikasi vegetasi dan NDVI

\begin{tabular}{llll}
\hline No & Kelas Kerapatan & Nilai NDVI & Skor \\
\hline 1 & Tinggi & $0.35-1$ & 3 \\
2 & Sedang & $0.15-0.35$ & 2 \\
3 & Rendah & $-1-0.15$ & 1 \\
\hline
\end{tabular}

Sumber: Nugroho (2016)

Tabel 3. Tingkat kerawanan kebakaran lahan

\begin{tabular}{lll}
\hline No & Jumlah skor & Tingkat kerawanan kebakaran \\
\hline 1 & $2-4$ & Rendah \\
2 & $5-7$ & Sedang \\
3 & $8-10$ & Tinggi \\
\hline
\end{tabular}

Sumber: Hasil pengolahan data (2020)

\section{Hasil dan Pembahasan}

Tutupan lahan menentukan tingkat kerawanan kebakaran hutan dan lahan. Wilayah dengan tutupan lahan berupa lahan pertanian, perkebunan dan semak belukar lebih rawan untuk terbakar daripada penggunaan lahan berupa hutan. Aktivitas manusia dalam menyiapkan lahan pertanian menyebabkan suatu wilayah rawan terhadap kebakaran lahan. Pada umumnya manusia menyiapkan lahan pertanian dengan membakar lahan. Pembuatan saluran drainase pada lahan terutama lahan gambut menyebabkan lahan terdrainase dan kering.

Tutupan lahan di Kecamatan Cempaka didominasi oleh pertanian lahan kering dan perkebunan, Kecamatan Banjarbaru Selatan didominasi oleh tutupan lahan berupa permukiman, Kecamatan Banjarbaru Utara didominasi oleh tutupan lahan berupa permukiman dan pertanian lahan kering, Kecamatan Landasan Ulin didominasi oleh tutupan lahan berupa permukiman, sawah, dan pertanian lahan kering, sedangkan Kecamatan Lianganggang didominasi oleh tutupan lahan berupa sawah, permukiman dan belukar rawa. Tutupan lahan di Banjarbaru terdapat pada Gambar 1 dan Tabel 4.

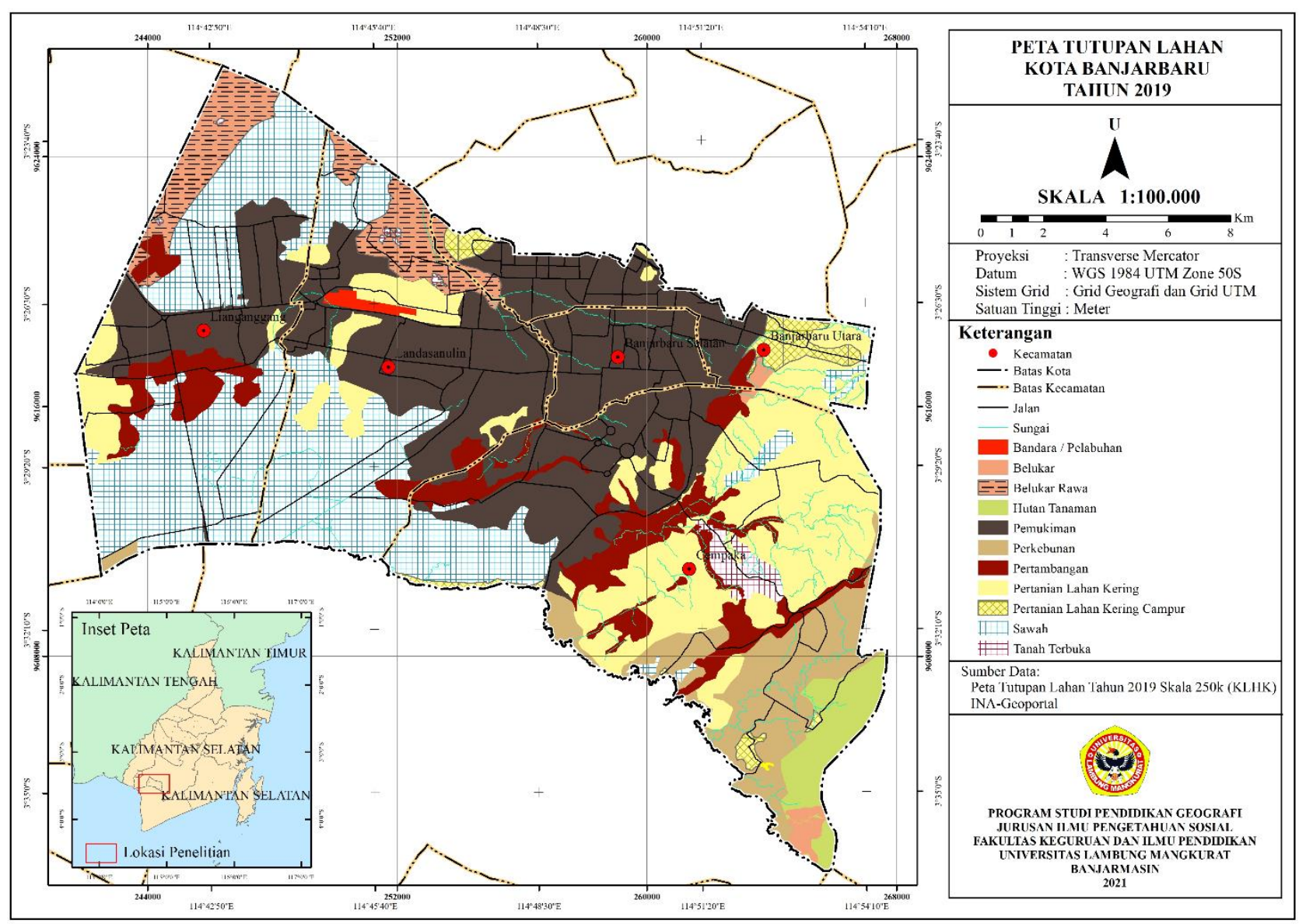

Gambar 1. Peta Tutupan lahan di Banjarbaru 
Tabel 4. Tutupan lahan di Banjarbaru

\begin{tabular}{|c|c|c|c|}
\hline Kecamatan & Tutupan lahan & Skor & Luas $(\mathrm{Ha})$ \\
\hline \multirow[t]{10}{*}{ Cempaka } & Hutan Tanaman & 6 & 853.36 \\
\hline & Belukar & 7 & 164.02 \\
\hline & Perkebunan & 5 & 2213.78 \\
\hline & Pemukiman & 7 & 2428.97 \\
\hline & Pertanian Lahan Kering & 6 & 3862.51 \\
\hline & Sawah & 7 & 1123.66 \\
\hline & Pertambangan & 2 & 1773.02 \\
\hline & Pertanian Lahan Kering Campur & 6 & 164.87 \\
\hline & Tanah Terbuka & 1 & 307.84 \\
\hline & Hutan Tanaman & 6 & 288.77 \\
\hline \multirow[t]{2}{*}{ Banjarbaru Selatan } & Pemukiman & 7 & 1495.21 \\
\hline & Pertambangan & 2 & 6.59 \\
\hline \multirow[t]{7}{*}{ Banjarbaru Utara } & Belukar & 7 & 44.99 \\
\hline & Pemukiman & 7 & 1465.12 \\
\hline & Belukar Rawa & 6 & 123.82 \\
\hline & Pertanian Lahan Kering & 6 & 505.66 \\
\hline & Sawah & 7 & 99.23 \\
\hline & Pertambangan & 2 & 60.59 \\
\hline & Pertanian Lahan Kering Campur & 6 & 464.98 \\
\hline \multirow[t]{7}{*}{ Landasan Ulin } & Pemukiman & 7 & 2915.40 \\
\hline & Belukar Rawa & 6 & 751.50 \\
\hline & Pertanian Lahan Kering & 6 & 764.51 \\
\hline & Sawah & 7 & 2631.54 \\
\hline & Pertambangan & 2 & 156.14 \\
\hline & Bandara / Pelabuhan & 1 & 106.56 \\
\hline & Tanah Terbuka & 1 & 27.05 \\
\hline \multirow[t]{7}{*}{ Lianganggang } & Pemukiman & 7 & 1607.41 \\
\hline & Belukar Rawa & 6 & 899.20 \\
\hline & Pertanian Lahan Kering & 6 & 529.98 \\
\hline & Sawah & 7 & 4323.89 \\
\hline & Pertambangan & 2 & 204.36 \\
\hline & Tanah Terbuka & 1 & 7.53 \\
\hline & Perkebunan & 5 & 59.20 \\
\hline
\end{tabular}

Tabel 5 dan Gambar 2 menunjukkan nilai NDVI pada tahun 2018. Hasil Normalized Difference Vegetation Index (NDVI) pada tahun 2018 menunjukkan bahwa nilai NDVI dengan nilai rentang $0.35-1$ (kerapatan vegetasi tinggi) paling luas terdapat di Kecamatan Cempaka, dan Lianganggang. Sedangkan Kecamatan Banjarbaru Selatan, Banjarbaru Utara dan Landasan Ulin didominasi oleh kerapatan vegetasi sedang. Kerapatan vegetasi tinggi mempunyai kerawanan kebakaran hutan dan lahan yang lebih tinggi daripada wilayah yang mempunyai kerapatan vegetasi sedang dan rendah. Hal ini berarti bahwa vegetasi yang akan mengalami kebakaran akan lebih banyak pada wilayah dengan kerapatan tinggi daripada lahan dengan kerapatan sedang dan rendah.

Tabel 6 dan Gambar 3 menjelaskan tentang tingkat kerawanan kebakaran hutan dan lahan di Banjarbaru. Tingkat kerawanan kebakaran hutan dan lahan ditinjau dari tutupan lahan dan kerapatan vegetasi didominasi oleh tingkat kerawanan tinggi. Tingkat kerawanan tinggi mempunyai areal yang paling luas di Kecamatan Cempaka berkisar $81.9 \%$, sedangkan tingkat kerawanan yang paling sedikit adalah kerawanan sedang dengan persentase sekitar $6.6 \%$. Tingkat kerawanan paling luas di Kecamatan 
Tabel 5. Kerapatan vegetasi sabarsabadi Banjarbaru tahun 2018

\begin{tabular}{lllr}
\hline Kecamatan & Kerapatan vegetasi & Skor & Luas (Ha) \\
\hline \multirow{3}{*}{ Cempaka } & Tinggi & 3 & 5735.07 \\
& Sedang & 2 & 6524.24 \\
& Rendah & 1 & 799.85 \\
\hline \multirow{3}{*}{ Banjarbaru Selatan } & Tinggi & 3 & 139.24 \\
& Sedang & 2 & 1155.14 \\
& Rendah & 1 & 207.42 \\
\hline \multirow{3}{*}{ Banjarbaru Utara } & Tinggi & 3 & 381.54 \\
& Sedang & 2 & 2007.35 \\
& Rendah & 1 & 375.52 \\
\hline \multirow{3}{*}{ Landasan Ulin } & Tinggi & 3 & 1076.74 \\
& Sedang & 2 & 5134.16 \\
& Rendah & 1 & 1141.83 \\
\hline \multirow{3}{*}{ Lianganggang } & Tinggi & 3 & 796.81 \\
& Sedang & 2 & 6383.70 \\
& Rendah & 1 & 1031.18 \\
\hline
\end{tabular}

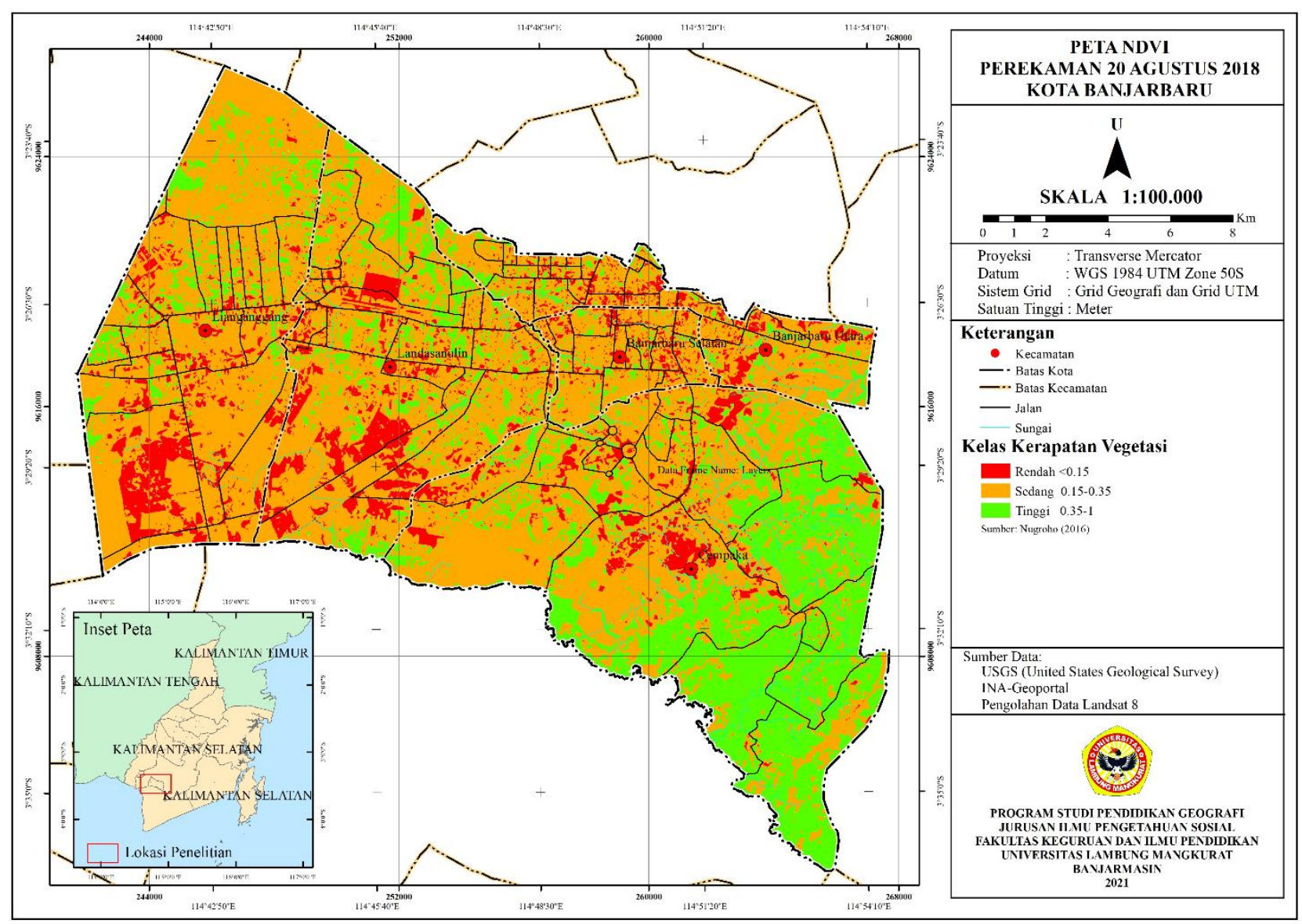

Gambar 2. Peta kerapatan vegetasi di Banjarbaru

Banjarbaru Selatan adalah kerawanan tinggi (99.5\%) dan paling sempit luasannya adalah kerawanan sedang $(0.2 \%)$. Tingkat kerawanan paling luas di Kecamatan Banjarbaru Utara adalah kerawanan tinggi (95.3 \%) dan paling sempit luasannya adalah kerawanan rendah $(2.1 \%)$. Tingkat kerawanan tinggi mempunyai areal yang paling luas di Kecamatan Landasan Ulin berkisar $94.1 \%$, sedangkan tingkat kerawanan yang paling sedikit adalah kerawanan sedang dengan persentase sekitar 2.0 persen. Tingkat kerawanan tinggi mempunyai areal yang paling luas di Kecamatan Lianganggang berkisar 88.9\%, 
Tabel 6. Tingkat kerawanan kebakaran hutan dan lahan di Banjarbaru

\begin{tabular}{llrr}
\hline Kecamatan & Kelas kerawanan & Luas (Ha) & Persentase (\%) \\
\hline Cempaka & Tinggi & 10515.89 & 81.9 \\
& Sedang & 844.83 & 6.6 \\
& Rendah & 1475.06 & 11.5 \\
\hline \multirow{2}{*}{ Banjarbaru Selatan } & Tinggi & 1495.21 & 99.5 \\
& Sedang & 2.33 & 0.2 \\
& Rendah & 4.25 & 0.3 \\
\hline \multirow{2}{*}{ Banjarbaru Utara } & Tinggi & 2635.12 & 95.3 \\
& Sedang & 70.64 & 2.6 \\
& Rendah & 58.65 & 2.1 \\
\hline \multirow{2}{*}{ Landasan Ulin } & Tinggi & 6920.12 & 94.1 \\
& Sedang & 146.76 & 2.0 \\
& Rendah & 285.83 & 3.9 \\
\hline \multirow{2}{*}{ Lianganggang } & Tinggi & 7305.12 & 88.9 \\
& Sedang & 145.22 & 1.8 \\
& Rendah & 763.47 & 9.3 \\
\hline
\end{tabular}

Sumber: Pengolahan Data (2020)

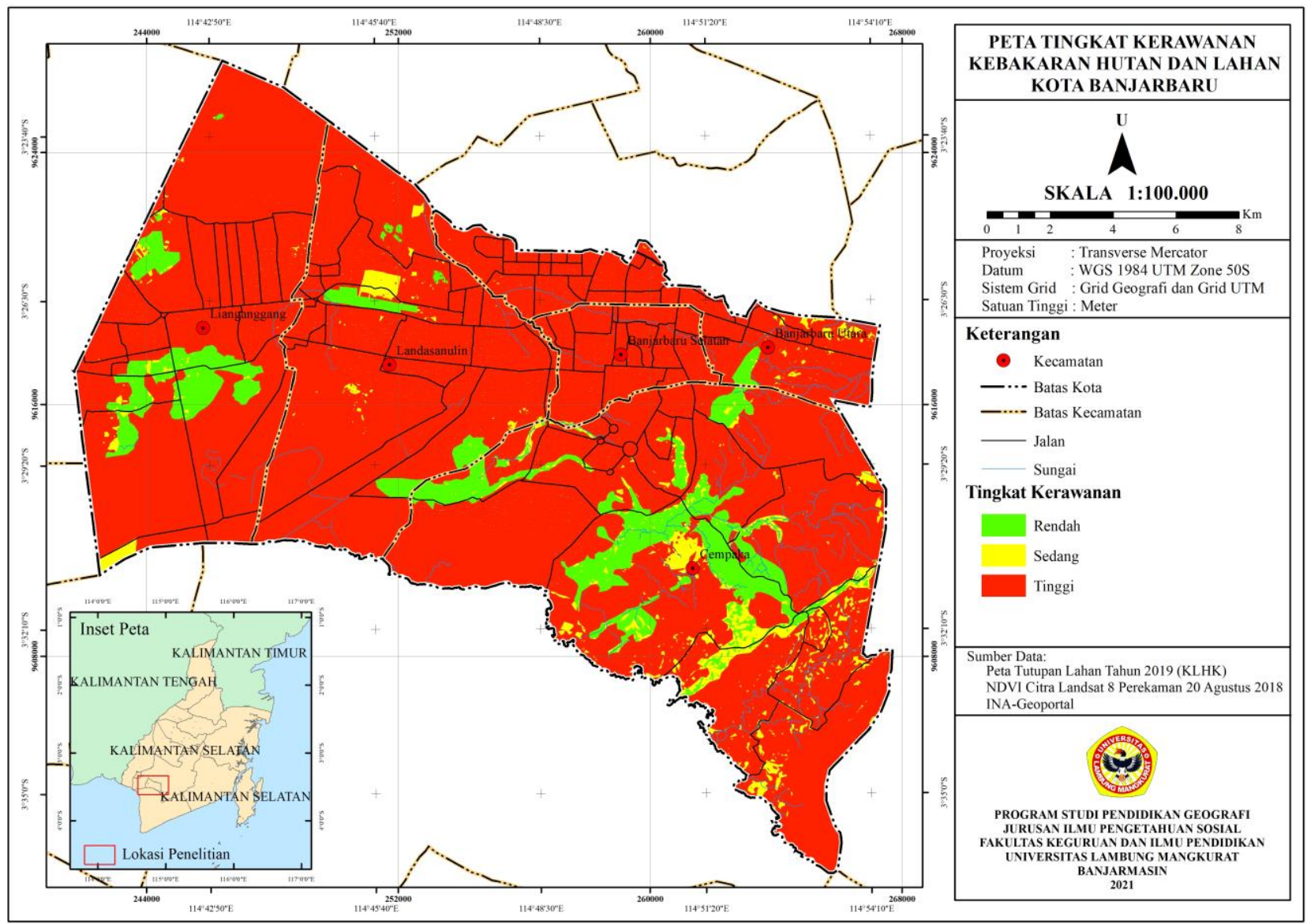

Gambar 3. Peta tingkat kerawanan kebakaran hutan dan lahan di Banjarbaru

sedangkan tingkat kerawanan yang paling sedikit adalah kerawanan sedang dengan persentase sekitar $1.8 \%$. Tutupan lahan yang didominasi oleh adanya lahan pertanian, perkebunan, dan semak belukar dengan kerapatan vegetasi yang sedang-tinggi menyebabkan tingkat kerawanan menjadi tinggi. Aktivitas manusia yang semakin meningkat seperti aktivitas pertanian dan perkebunan menyebabkan tingkat kerawanan kebakaran semakin tinggi. 

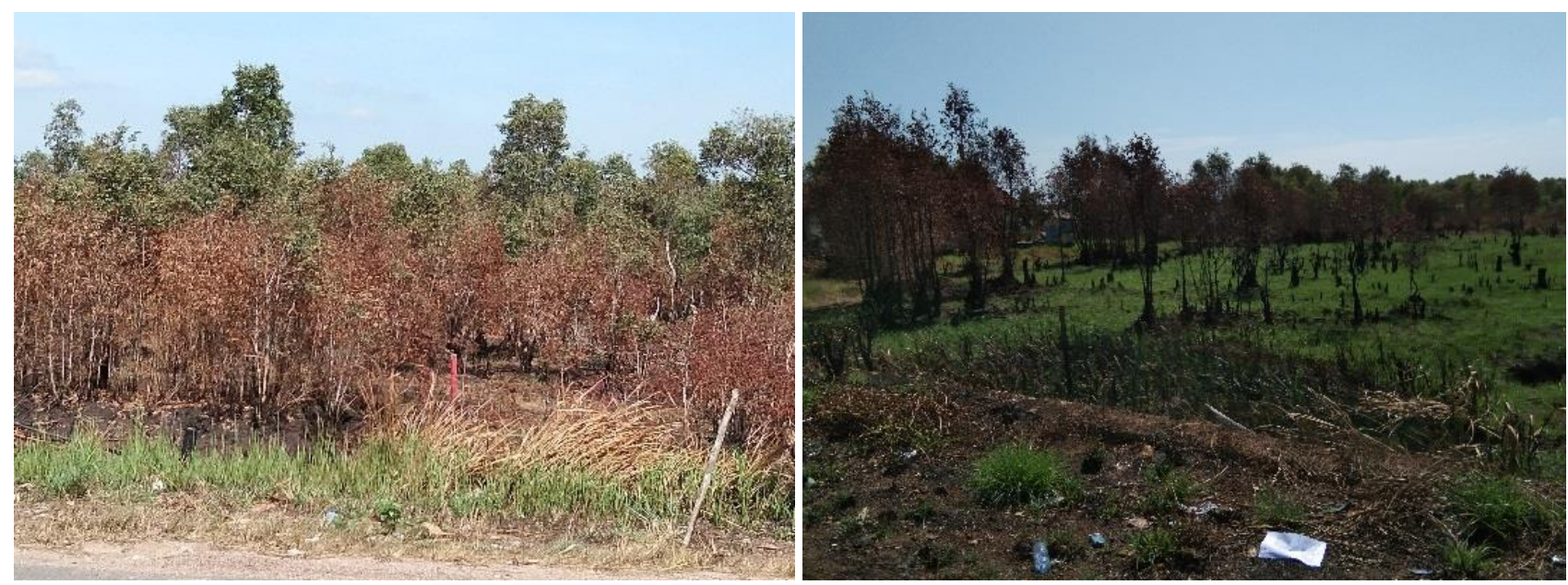

Gambar 4. Kebakaran pada penggunaan lahan semak belukar di Kecamatan Lianganggang

Pada musim kemarau, wilayah Banjarbaru selalu mengalami kebakaran hutan dan lahan (Gambar 4). Adanya curah hujan yang rendah pada musim kemarau telah menyebabkan kebakaran mudah terjadi (Arisanty et al., 2020). Bulan Desember tahun 2018 mempunyai curah hujan paling tinggi yaitu 434.3 $\mathrm{mm}$, sedangkan bulan Mei tahun 2018 mempunyai curah hujan yang paling rendah yaitu $76 \mathrm{~mm}$. Curah hujan tahun 2018 adalah $2515.8 \mathrm{~mm} /$ tahun. Curah hujan bulanan rata-rata adalah $210 \mathrm{~mm}$. Kebakaran biasanya akan terjadi pada bulan Juli-Oktober karena pada bulan tersebut lahan sudah mulai kering dan hujan juga sudah sedikit.

Kecepatan angin di Banjarbaru yang paling tertinggi yaitu pada bulan Januari dengan kecepatan mencapai $6.4 \mathrm{~m} / \mathrm{s}$. sedangkan kecepatan angin terendah terdapat pada bulan Juli yang hanya mencapai kecepatan $2 \mathrm{~m} / \mathrm{s}$. Rata-rata kecepatan angin di Banjarbaru adalah $3.316 \mathrm{~m} / \mathrm{s}$. Kecepatan angin akan mempercepat dan memperluas lahan yang terbakar. Pada saat kecepatan angin tinggi, maka angin akan menurunkan kelembaban udara, sehingga api berkobar dan merambat dengan cepat ke lokasi lain yang belum terbakar (Hadiprasetya, 2009). Kecepatan angin pada musim kemarau termasuk kriteria sedang sehingga areal yang terbakar mempunyai peluang lebih cepat dan luas.

Kebakaran hutan dan lahan mempunyai dampak yang besar terhadap lingkungan seperti terjadinya penurunan keanekaragaman hayati, penurunan kualitas tanah, dan terjadinya perubahan iklim. Oleh karena itu, upaya perlindungan terhadap kawasan hutan sangatlah penting untuk mengurangi dampak dari kebakaran hutan dan lahan tersebut. Pemetaan terhadap wilayah yang rawan terhadap kebakaran sangat bermanfaat dalam pengambilan keputusan terkait dengan upaya dalam mengatasi kebakaran hutan dan lahan (Putra et al., 2018).

\section{Kesimpulan}

Tingkat kerawanan kebakaran di tinjau dari tutupan lahan dan kerapatan vegetasi didominasi oleh tingkat kerawanan tinggi di semua kecamatan yang ada di Banjarbaru. Tingkat kerawanan tinggi di Kecamatan Cempaka adalah 81.9 \%, di Kecamatan Banjarbaru Selatan berkisar 99.5 \%, di Kecamatan Banjarbaru Utara berkisar 95.3 \%, di Kecamatan Landasan Ulin berkisar $94.1 \%$ dan di Kecamatan Lianganggang berkisar $88.9 \%$. Wilayah yang rawan kebakaran hutan dan lahan mempunyai tutupan lahan berupa lahan pertanian, perkebunan dan semak belukar dengan tutupan vegetasi mempunyai kerapatan sedang-tinggi. Aktivitas manusia yang meningkat menyebabkan tingkat kerawanan kebakaran juga semakin tinggi.

\section{Referensi}

Arisanty, D., Adyatma, S., Muhaimin, M., \& Nursaputra, A. (2019). Landsat 8 OLI TIRS Imagery Ability for Monitoring Post Forest Fire Changes. Pertanika Journal of Science \& Technology, 27(3), 1105-1120. https://doi.org/2231-8526

Arisanty, D., Anis, M. Z. A., Putro, H. P. N., Hastuti, K. P., \& Angriani, P. (2021). Social Vulnerability of Land Fires in Banjarbaru. The 2nd International Conference on Social Sciences Education (ICSSE 2020), 262-265.

Arisanty, D., JĘDRASIAK, K., Rajiani, I., \& Grabara, J. (2020). The Destructive Impact of Burned Peatlands to Physical and Chemical Properties of Soil. Acta Montanistica Slovaca, 25(2), 213-223. 
https://doi.org/10.46544/AMS.v25i2.8

Certini, G. (2005). Effects of fire on properties of forest soils: a review. Oecologia, 143(1), 1-10.

Endrawati, E., Purwanto, J., Nugroho, S., \& Agung, R. (2018). Identifikasi areal bekas kebakaran hutan dan lahan menggunakan analisis semi otomatis citra satelit LANDSAT. Seminar Nasional Geomatika, 2, 273-282.

Hadiprasetya, Y. (2009). Identifikasi faktor penyebab kebakaran hutan dan upaya penanggulangannya di taman nasional gunung ciremai, jawa barat [Skripsi]. Departemen Silvikultur Fakultas Kehutanan Institut Pertanian Bogor.

Harrison, M. E., Page, S. E., \& Limin, S. H. (2009). The global impact of Indonesian forest fires. Biologist, 56(3), 156-163.

Jawad, A., Nurdjali, B., \& Widiastuti, T. (2015). Zonasi daerah rawan kebakaran hutan dan lahan di Kabupaten Kubu Raya Provinsi Kalimantan Barat. Jurnal Hutan Lestari, 3(1).

Murtinah, V., Edwin, M., \& Bane, O. (2017). Dampak kebakaran hutan terhadap sifat fisik dan kimia tanah di Taman Nasional Kutai, Kalimantan Timur. Jurnal Pertanian Terpadu, 5(2), 128-139.

Novita, S. E., \& Vonnisa, M. (2021). Pemodelan Spasial Kerentanan Kebakaran Hutan dan Lahan di Kalimantan Timur. Jurnal Fisika Unand, 10(2), 232-238.

Nugroho, A. (2016). Analisis Kerapatan Vegetasi di Kecamatan Ngaglik Tahun 2006 dan 2016 Menggunakan Teknik Penginderaan Jauh. Analisis Kerapatan Vegetasi, 2, 306-320.

Putra, A., Tri Ratnaningsih, A., \& Ikhwan, M. (2018). Pemetaan Daerah Rawan Kebakaran Hutan dan Lahan Dengan Menggunakan Sistem Informasi Geografis (Studi Kasus: Kecamatan Bukit Batu, Kab. Bengkalis). Wahana Forestra: Jurnal Kehutanan, 13(1), 55-63.

Rauf, A. (2016). Dampak kebakaran lahan perkebunan kelapa sawit di lahan gambut Kabupaten Aceh Barat Daya terhadap sifat tanah gambut. Jurnal Pertanian Tropik, 3(3), 256-266.

Razali, S. M., Nuruddin, A. A., Malek, I. A., \& Patah, N. A. (2010). Forest fire hazard rating assessment in peat swamp forest using Landsat thematic mapper image. Journal of Applied Remote Sensing, 4(1), 43531.

Sabaraji, A. (2005). Identifikasi Zone Rawan Kebakaran Hutan dan Lahan dengan Aplikasi SIG di Kabupaten Kutai Timur. Universitas Mulawarman. Samarinda.

Sahani, M., Zainon, N. A., Mahiyuddin, W. R. W., Latif, M. T., Hod, R., Khan, M. F., Tahir, N. M., \& Chan, C.-C. (2014). A case-crossover analysis of forest fire haze events and mortality in Malaysia. Atmospheric Environment, 96, 257-265.

Saharjo, B. H., \& Velicia, W. A. (2018). The Role of Rainfall Towards Forest and Land Fires Hotspot Reduction in Four Districs in Indonesia on 2015-2016. Jurnal Silvikultur Tropika, 9(1), 24-30.

Siegert, F., \& Hoffmann, A. A. (2000). The 1998 forest fires in East Kalimantan (Indonesia): a quantitative evaluation using high resolution, multitemporal ERS-2 SAR images and NOAAAVHRR hotspot data. Remote Sensing of Environment, 72(1), 64-77.

Sitanggang, I. S., Yaakob, R., Mustapha, N., \& Ainuddin, A. N. (2013). Predictive models for hotspots occurrence using decision tree algorithms and logistic regression. Journal of Applied Sciences, 13(2), 252-261.

Sitanggang, Yaakob, R., Mustapha, N., \& AN, A. (2014). A Decision Tree Based on Spatial Relationships for Predicting Hotspots in Peatlands. Telkomnika, 12(2).

Tacconi, L., Jotzo, F., \& Grafton, R. Q. (2008). Local causes, regional co-operation and global financing for environmental problems: the case of Southeast Asian Haze pollution. International Environmental Agreements: Politics, Law and Economics, 8(1), 1-16. 